\section{Produção e circulação do discurso Contra Eunômio a partir dos Exilium e Relegatio de Gregório de Nissa (século IV d. C.)*}

\author{
Production and circulation of the speech Adversus Eunomium \\ based on the exilium and relegatio de Gregory of Nyssa
}

(IV century AD)

Helena Amália Papa**

\begin{abstract}
Resumo: Durante muito tempo, a historiografia analisou os documentos de Gregório de Nissa (335/340-394 d. C.) como apêndice para os escritos dos outros dois Padres Capadócios: Basílio de Cesareia e Gregório de Nazianzo. Este artigo tem o objetivo de compreender o período de produção e circulação do discurso Contra Eunômio de Gregório de Nissa a partir de eventos vivenciados pelo próprio autor. Dessa maneira, intentamos relacionar os períodos de exilium e relegatio de Gregório com a produção e circulação de seu discurso Contra Eunômio.
\end{abstract}

\begin{abstract}
During a long time, the historiography has analyzed the documents of Gregory of Nyssa (335/340-394 AD) as an appendix to the writings of the other two Cappadocian Fathers: Basil of Caesarea and Gregory of Nazianzus. This article aims to understand the period of production and circulation of the Gregory of Nyssa's discourse Adversus Eunomium based on some events experienced by the author. Thus, we aimed to relate the Gregory's periods of exilium and relegatio with the production and circulation of his discourse Adversus Eunomium.
\end{abstract}

\section{Palavras-chave: \\ Antiguidade Tardia; \\ Exilium; \\ Relegatio; \\ Gregório de Nissa; \\ Contra Eunômio.}

\section{Keywords:}

Late Antiquity;

Exilium;

Relegatio;

Gregory of Nyssa;

Adversus Eunomium.

Recebido em: 21/06/2013

Aprovado em: 01/07/2013

\footnotetext{
* Agradecemos o convite do Prof. Dr. Gilvan Ventura da Silva e da Profa. Me. Carolline Soares para compor esse dossiê. Estendemos o agradecimento à constante orientação da Profa. Dra. Margarida Maria de Carvalho.

** Doutoranda do Programa de pós-graduação em História e Cultura Política pela Universidade Estadual Paulista "Júlio de Mesquita Filho", Campus de Franca (UNESP/Franca), com apoio da Fapesp.
} 


\section{Introdução}

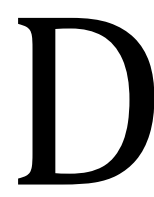
entre as muitas discussões teológicas que ocorreram no século IV d. C., o presente artigo debruça-se sobre aquela que pretendeu dar uniformidade e sentido ao dogma trinitário por meio das discussões sobre a divindade da segunda pessoa da Trindade, ${ }^{1}$ Jesus Cristo, praticada por dois grupos cristãos que possuíam visões diferentes sobre essa questão. Trata-se de um embate entre os cristãos arianos e cristãos nicenos, personificados, nessa investigação, pelos bispos, o niceno Gregório de Nissa (335/340-394 d. C.) e o ariano Eunômio de Cízico (335-394d. C.).

Nosso intento é analisar os meandros de produção e circulação do discurso Contra Eunômio (Livro 1) de Gregório de Nissa, a fim de compreender as relações de poder que se complementavam e se contrastavam com o objetivo de serem aceitas como corretas (ortodoxas) pelos seus pares e pelo poder imperial. O conflito é apresentado pela historiografia como apêndice de outra querela ocorrida em torno de duas décadas antes entre o mesmo bispo ariano, Eunômio de Cízico, e Basílio de Cesareia (329/331-379 d. C.), irmão do mencionado Gregório.

Sendo assim, propomos um olhar diferenciado para a contenda envolvendo Gregório e Eunômio: antes de analisá-la como apêndice do debate que envolveu o seu irmão, pretendemos compreender as condições de produção do Contra Eunômio 1, de Gregório de Nissa, a partir do contexto e acontecimentos dos quais o próprio Gregório participou, dados esses que procuramos detectar nos seus próprios discursos. Queremos dizer que levamos em consideração que tal discurso também atuou como uma resposta de Gregório de Nissa aos ataques que Eunômio teria feito ao seu irmão Basílio. Assim, configuramos nossos objetivos, pretendendo analisar outros meandros e possíveis intentos de Gregório com a produção e circulação de seu discurso.

Dessa maneira, estruturamos nossa hipótese: Gregório de Nissa escreveu o seu discurso Contra Eunômio como forma de autopromoção e autoafirmação a fim de que a sua imagem entre os cristãos nicenos e, na condição de partícipe desse grupo, defensor da ortodoxia, fosse restabelecida após Gregório enfrentar um período de exílio, prisão e consequente distanciamento físico do jogo político-religioso que ocorria naquele contexto. Entendemos por político-religioso a intersecção que essas esferas tinham na

\footnotetext{
${ }^{1}$ Esse artigo faz parte de uma proposta maior, que inclui nosso projeto de doutorado, atualmente em execução, orientado pela Profa. Dra. Margarida Maria de Carvalho (UNESP/Franca) com apoio da Fapesp.
} 
vida da população e na dinâmica das relações de poder. Acrescenta-se que, cerca de três anos após o exílio, Gregório de Nissa é nomeado "restaurador da fé nicena" pelo imperador Teodósio I, citado nominalmente na Constitutio XVI, 1, 3 do Código Teodosiano, datada de $381 \mathrm{~d}$. C., como notamos abaixo:

Cod. Theod. XVI, 1, 3 (30 de julho de 381)

Dos Imperadores Graciano, Valentiniano [II] e Teodósio [I], Augustos, a Auxônio, proconsul da Ásia.

Nós ordenamos para transmitir para todas as igrejas, que bispos confessem que o Pai, o Filho e o Santo Espírito são somente uma majestade, uma única energia, uma glória. Que eles não estabeleçam nenhuma diferença por uma distinção ímpia, mas que eles reconheçam o decreto da Trindade pela afirmação das pessoas e a unidade da divindade para esses bispos que estão em comunhão com [...] aqueles da Diocese do Ponto, Heládio de Cesareia; Otreio de Melitene; Gregório de Nissa, Terênio, bispo de Cítia; Mármário, bispo de Marcianópolis. Eles devem obter o encargo das igrejas católicas, já que estão em comunhão e associação com esses bispos de vida recomendável. Todos aqueles que estão em desacordo com a comunhão da lei dos bispos [...] serão expulsos das igrejas como heréticos notórios. [...]. Que os santos ministros mantenham a verdade na lei de Niceia e que depois desse mandamento ninguém faça nem receba uma manobra fraudulenta (grifo nosso).

Diante do exposto, temos como objetivo, nesse artigo, apresentar algumas considerações relacionadas à temática do exílio no século IV d. C. para, em seguida, apresentar uma possibilidade de análise do discurso de Gregório de Nissa, envolvendo seus momentos de exílio e prisão, relacionando-os com a produção e circulação de seu discurso Contra Eunômio.

\section{Considerações sobre exilium, relegatio e deportatio}

Na primeira década do século IV d. C., após períodos de interdição ao cristianismo no Império Romano, os cristãos, assim como outros grupos, tiveram a sua crença colocada na legalidade, sob a ótica da legislação do Império. Mas, ao invés de um período de Paz na Igreja, como proclamou a historiografia durante muito tempo, houve, no século IV d. C., a multiplicação de controvérsias e cismas teológicos (SILVA, 
2006). Assim, após 312 d. C., conforme María Victoria Escribano Paño (2003, p. 178-179): "a interdição de ser cristão deu lugar à redefinição das noções de ortodoxia e heresia e à transformação dos métodos de debate entre os cristãos".

As intervenções do imperador Constantino no cisma donatista e na controvérsia ariana e o contínuo patrocínio imperial reforçaram o papel de autoridade que os bispos adquiririam, de forma crescente, no decorrer do século IV d. C. Dessa forma, na controvérsia ariana, além da base teológica do dogma trinitário, o que também estava em discussão nos sínodos e concílios era o cargo mais proeminente na hierarquia eclesiástica nesse momento: o episcopos. Assim, por meio de deposições e exílios, as autoridades eclesiásticas disputavam as sedes episcopais.

Peter Van Nuffelen (2008, p. 148), em um capítulo acerca das dimensões jurídicas e políticas do retorno do exílio no século IV $\mathrm{d}$. C., pretendeu mostrar as divergências que permeavam o exílio, como pena imperial e condenação eclesiástica. Por meio de vários estudos de caso, esse historiador belga mostrou que um bispo deposto por seus pares em um concílio não seria necessariamente exilado, assim como não era regra que um bispo exilado tivesse sido anteriormente condenado pelos seus pares em um concílio. Logo, a esfera religiosa não poderia impor um exílio como pena, e nem o poder imperial, por mais que houvesse o entrelaçamento entre o político e o religioso nesse momento. Segundo Nuffelen, a relação e influência entre a pena imperial e a condenação eclesiástica são inegáveis durante o século IV d. C., mas isso não pode ser visto como regra.

Nessa relação entre o papel do Estado e da religião é que Escribano Paño (2003, p. 180) adiciona à controvérsia ariana as disputas individuais entre os eclesiásticos e o enfrentamento entre o poder imperial e os bispos nesse momento de redistribuição de poder no Império Romano e afirmação do papel e do discurso dos bispos cristãos.

Em primeira instância, objetiva-se, com o exílio, o distanciamento e separação do considerado errante do conflito em questão, constituindo-se o exílio uma manifestação de intolerância e um instrumento de repressão contra o oponente. No tocante às consequências dessa penalidade, todavia "[...] a experiência do afastamento geográfico deu lugar a uma intensa circulação de pessoas e ideias e contribuiu para a expansão daquilo que se pretendia combater" (ESCRIBANO PAÑO, 2003, p. 183).

Roland Delmaire (2008) traz uma importante contribuição à temática ao realizar um estudo, nos códigos legislativos, acerca da relação entre o delito e a pena de exílio, 
relegação e deportação no período que ele denomina de Baixo Império. Para entender as diferenças jurídicas entre exilium, relegatio e deportatio utilizaremos os vocábulos em português: exílio-banimento, exílio-relegação (como sinônimo de desterro) e deportação; bem como a análise dos autores supracitados.

No exílio-banimento era interditada ao exilado a permanência em determinado lugar, que poderia ser uma cidade, província ou região específica do Império Romano. Nesse caso, o exilado guardava seus direitos cívicos e poderia circular em outros lugares, excetuando-se o local específico do qual foi banido. Como exemplificação, Delmaire (2008, p. 116) aponta esse tipo jurídico como majoritário nas querelas religiosas.

Já no exílio-relegação, o exilado não era livre para circular, sendo obrigado a permanecer em um local determinado por um período específico, como, por exemplo, em uma cidade, província ou região. Assim como no exílio-banimento, os seus direitos cívicos seriam mantidos. Segundo Delmaire (2008, p. 121), o relegado a esse tipo de exílio deveria partir para o local determinado sob a escolta de autoridades militares, provinciais e municipais.

No tocante à deportação, além do desterro definitivo, essa condição jurídica era acompanhada pela confiscação dos direitos civis e dos bens, exceto de uma pequena quantia para subsistência. Delmaire (2008, p.122) apresenta as modificações que essa condição jurídica sofreu ao longo do século IV d. C., bem como os valores que seriam confiscados, caso o condenado tivesse família e filhos.

Ao analisar os casos de bispos que retornaram do exílio, Van Nuffelen (2008, p. 147) utilizou-se de casos de exílio, do tipo relegação e banimento, para mostrar "a importância de uma dimensão política vista pela ótica de uma decisão jurídica". Nessa visão, com a anistia ou indulgência de algum imperador, seja pela morte de seu antecessor, ou por uma postura político-religiosa diferente, o retorno desses bispos traria uma conotação política à dimensão jurídica, que nós estendemos à religiosa: ao retornar, o exilado reclamaria sua posição anterior ao poder civil, bem como aos seus pares, contribuindo ainda mais para a efervescência político-religiosa desses conflitos.

Logo, a relação entre o político e o jurídico apontada por Van Nuffelen e Escribano Paño se faz presente, uma vez que o exílio pode ser equiparado, nesse momento, à instrumentalização de uma "marginalização geográfica" como método para tentar resolver as rivalidades religiosas. Nesse "afastamento forçoso conflui tanto uma 
tradição jurídica penal como os procedimentos de um inimigo político" (ESCRIBANO PAÑO, 2003, p. 207).

\section{Os exílios de Gregório de Nissa e a produção do Contra Eunômio}

As notícias biográficas de Gregório de Nissa são poucas quando comparadas às de outros bispos que viveram nessa época e local, por exemplo, seu irmão Basílio de Cesareia e seu amigo Gregório de Nazianzo. Juntos, os três ficaram conhecidos pela historiografia e literatura patrística como Padres Capadócios, fazendo jus à província em que nasceram: a Capadócia.

Provavelmente, Gregório nasceu na mesma cidade do irmão, Neocesareia, cidade próxima a Cesareia (Bas. Ces., Epistula 210), Capital da Capadócia da Ásia Menor (atual Turquia) entre 335-340 d. C., em uma família rica e cristã que sofreu perseguições durante o governo tetrárquico de Diocleciano.

Assim, como seus irmãos Basílio e Pedro, recebeu os primeiros ensinamentos da irmã mais velha, Macrina (Greg. Nis., Vita Macrina 12), posteriormente de seu irmão Basílio (Greg. de Nis., Vit. Mac., 6) até completar os seus estudos na Escola de Cesareia. Assim como seu pai, Basílio, o Velho e seu irmão Basílio, exerceu a profissão de rétor. ${ }^{2}$

Apesar de não termos notícias de sua ordenação como sacerdote, sabemos que seu irmão Basílio, bispo de Cesareia desde 370 d. C., Ihe impôs a sede episcopal da cidade de Nissa. Ressaltamos que o cargo episcopal de Basílio era de grande importância. Cesareia não era apenas a metrópole eclesiástica da Capadócia, pois abrangia ao todo onze províncias, ou seja, quase metade da Ásia Menor. Compartilhamos essa ideia com Hubertus Drobner (2003) e Michel Spanneut (2002), que, ao discutirem acerca do prestígio e poder que Basílio possuía, nos dão informações a respeito da importância do cesareno em ocupar a diocese da Capadócia, desempenhando praticamente a função do que viria a ser o patriarca, no século VI, de toda a diocese civil do Ponto (SPANNEUT, 2002, p. 36; DROBNER, 2003, p. 279). Daniel de Figueiredo (2012, p. 33) nos informa que o termo patriarcado não existia antes do

\footnotetext{
${ }^{2}$ Espécie de advogado e professor. Os professores de retórica se consideravam primordiais na preparação dos que ocupariam altos cargos administrativos, religiosos e os que tinham chance de chegar ao cargo de imperador. Sobre o assunto ver SPINELLI, 2002, p. 294 e CARVALHO, 2010, p. 29.
} 
século VI d. C., mas o mesmo já podia ser detectado antes desse período mediante o desenvolvimento de territórios e fronteiras em torno de uma sede episcopal.

Com essa autoridade e legitimidade foi que, em 372 d. C., Basílio impôs ao seu irmão Gregório o episcopado da cidade de Nissa (Greg. Naz., Ep. 11). Durante esse ano, Basílio e sua província, a Capadócia, sofreram uma impactante intervenção imperial: o imperador Valente, governante da porção oriental do Império Romano, mostrava-se favorável aos arianos. Dando continuidade às reformas administrativas e fiscais iniciadas por Diocleciano nas províncias do Império Romano, e certamente visando a enfraquecer os bispos nicenos mais influentes, o então imperador Valente dividiu a província da Capadócia em duas, ou seja, dividiu a província civil a fim de, também, prejudicar a diocese eclesiástica, governada por Basílio (Bas. Ces., Ep. 74, 75, 76, 97 e 99).

Nesse contexto foi que Basílio criou novas sedes episcopais a fim de tentar restabelecer sua influência e prestígio na segunda Capadócia (DROBNER, 2003, p. 289). Como exemplo, citamos a ordenação do amigo Gregório de Nazianzo ao episcopado da cidade de Sásima (Bas. Ces., Ep. 98).

Ainda sob o governo de Valente e em nome da querela político-religiosa, Gregório de Nissa foi condenado ao exílio em 375-376 d. C. (Bas. Ces., Ep. 231, 232 e 239) por decisão de um tribunal comandado pelo vicário da diocese civil do Ponto, Demóstenes (Bas. Ces., Ep. 225 e 237), cuja pena foi revertida apenas após a morte de Valente, em 378-379 d. C., quando o novo governante, o imperador Teodósio, defensor da fé nicena, absolveu os bispos exilados. Nesse momento é que Gregório começou a escrever o discurso Contra Eunômio, composto por 3 livros e finalizado em meados de 383 d. C.

Somente após a morte de Basílio, em 378 d. C., e de sua irmã Macrina, em 380 d. C., é que possuímos notícias da atuação político-religiosa de Gregório de Nissa. Logo após a sanção do exílio, o nisseno teve uma ativa participação no Sínodo de Antioquia de $379 \mathrm{~d}$. C., o que the rendeu elogios pela historiografia como "homem de destaque e de confiança episcopal" (SPANNEUT, 2002, p. 69). Após esse episódio temos notícias de que Gregório viajou para um sínodo na cidade de Sebástia, por ocasião de uma sucessão episcopal. Durante a estada nessa cidade, por meio de "ataque herético" (Greg. Nis., Ep. 19, 13-14), o bispo ficou preso por aproximadamente três meses por autoridades civis, que obtinham, nesse momento, uma posição favorável diante de Valente. 
Posteriormente, Gregório participou de forma ativa nos preparativos do Concílio de Constantinopla, de $381 \mathrm{~d}$. C., que fixou as bases legais para o estabelecimento oficial da fé nicena em todo o Império Romano.

Somente após esses episódios é que podemos perceber, ao menos pelos documentos que chegaram até nós, que Gregório de Nissa ganhou visibilidade e passou a ter inserção na corte imperial, sendo considerado um homem de confiança e conselheiro espiritual do imperador nos assuntos religiosos. Teodósio (379-395 d. C.) Ihe concedeu um lugar de referência nos assuntos da fé nicena, como vemos na supracitada Constitutio XVI, 1, 3. Por determinação imperial, Gregório viajou por várias cidades do Império com o intuito de conter disputas teológicas entre nicenos e heterodoxos, principalmente contra Eunômio e seus discípulos.

Gregório de Nissa permaneceu na corte até aproximadamente 387 d. C., atuando em outros concílios a favor da ortodoxia. Após fixar-se em Milão, temos notícias que retornou a Constantinopla em 394 d. C., sendo este o último dado biográfico acerca do bispo; devido a esse fato é que a historiografia considera essa data a de seu falecimento.

No que diz respeito ao tema desse artigo, temos notícias dos dois momentos de exílio de Gregório de Nissa por meio de seu próprio testemunho (as seções 15 e 21 do discurso Vida de Santa Macrina; cinco epístolas, a saber: 5, 6, 18, 19 e 22 e a seção 125 do discurso Contra Eunômio, 1); por meio das epístolas 225, 231, 232 e 239 de seu irmão Basílio de Cesareia e através do testemunho de Gregório de Nazianzo deixado nas suas epístolas 72, 73, 74 e 76.

Como serão passíveis de observação, esses excertos relatam momentos difíceis, de confinação e privações que Gregório de Nissa teria passado. Esses dois momentos foram vistos e retratados na historiografia de modo uniforme e, quando diferenciados, são relacionados genericamente como períodos de exílio e/ou de prisão. A partir desses testemunhos e de informações sobre o contexto pudemos separar esses dois momentos de exílio de Gregório de Nissa mediante uma releitura cronológica de sua correspondência e de uma análise crítica, apoiadas numa historiografia recente que discute e propõe novas datações para as cartas de Basílio e Gregório de Nazianzo. Vale ressaltar que as últimas compilações críticas do epistolário do nazianzeno, pela Les Belles Lettres, é a de 1964; a de Basílio de Cesareia, pela mesma editora, é de 19571966, sendo que a de Gregório de Nissa, pela Les Editions du Cerf, é de 1994. Com base 
em recentes compilações críticas de várias obras de Gregório de Nissa (por exemplo, O Contra Eunômio 1, composto por 2 volumes, é de 2008 e 2010), muitas datações dos outros dois capadócios, Basílio e Nazianzeno, estão sendo atualmente discutidas pela historiografia.

Na tabela 1, abaixo, apresentamos uma breve catalogação de excertos referentes aos dois períodos de afastamento forçoso impostos a Gregório de Nissa. Pode-se perceber o nosso objetivo em detectar esses afastamentos como dois eventos separados, que apresentam cronologia e características diferentes, conforme tentaremos mostrar por meio das passagens citadas na tabela.

Tabela 1: Períodos de afastamentos forçosos impostos a Gregório de Nissa.

\begin{tabular}{|c|c|c|c|}
\hline & Período & Características & Documentação \\
\hline \multirow{11}{*}{$\begin{array}{l}\text { EXÍLIO- } \\
\text { BANIMENTO }\end{array}$} & \multirow{11}{*}{$376-378$} & \multirow{11}{*}{$\begin{array}{l}\text { Exilado fora da cidade } \\
\text { de Nissa, provavelmente } \\
\text { fora da fronteira da } \\
\text { Província Capadócia. }\end{array}$} & Gregório de Nissa \\
\hline & & & $V S M, 21$ \\
\hline & & & Gregório de Nissa \\
\hline & & & Epistulas 6 e 18 \\
\hline & & & Gregório de Nissa \\
\hline & & & CEI, 125 \\
\hline & & & Basílio de Cesareia \\
\hline & & & Epistulas 225, 231, 232, \\
\hline & & & 237,239 \\
\hline & & & Gregório de Nazianzo \\
\hline & & & Epistulas 72, 73, 74, 76 \\
\hline \multirow{5}{*}{$\begin{array}{l}\text { EXÍLIO- } \\
\text { RELEGAÇÃO }\end{array}$} & \multirow{5}{*}{380} & \multirow{5}{*}{$\begin{array}{l}\text { Preso por } 3 \text { meses na } \\
\text { cidade de Sebástia, } \\
\text { presença de escolta } \\
\text { militar. }\end{array}$} & \\
\hline & & & Gregório de Nissa \\
\hline & & & VSM, 15 \\
\hline & & & Gregório de Nissa \\
\hline & & & Epistulas 5, 19, 22 e 28 \\
\hline
\end{tabular}


Exemplificações de excertos do período de exílio-banimento (376-378 d. C.):

Da minha parte, eu disse a ela [Macrina] as dificuldades em que eu me encontrava quando o Imperador Valente me exilou por causa da sua fé, quando a confusão nas igrejas me convocou para as controvérsias e lutas (Greg. Nis., Vit. Mac., 21, 1-5).

O tribunal nos desprezou e seu poder, emudecido pelos insultos de Filocares, ordenou acusar e exilar nosso irmão e colega Gregório (Bas. Ces., Ep., 225, datada em 375 d. C., enviada ao funcionário imperial Demóstenes).

Um vicário [Demóstenes] chegou: foi o primeiro e o maior dos infelizes. Se esse homem tem sentimentos heréticos, eu não sei; em todo o caso ele é amigo dos heréticos e ele aprova com afeição que eles nos odeiem [...] (Bas. Ces., Ep., 237, 2, datada em 376 d. C., enviada ao bispo Eusébio de Samosata).

Estamos todos aflitos convosco. Confie na bondade de Deus e nas nossas preces que a tempestade se torne em brisa, e que o Deus da ortodoxia vos recompensará pelo triunfo diante dos caluniadores (Greg. Naz., Ep., 74, datada em 375 d. C., enviada a Gregório de Nissa).

Exemplificações de excertos do período de exílio-relegação (380 d. C.):

Nove meses, ou um pouco mais, após o luto [morte de Basílio], ocorreu um sínodo de bispos em Antioquia, dentre os quais fizemos parte. $\mathrm{E}$ então, passado um ano, nós estávamos livres para retornar à sua casa [de Macrina] [...]. Durante longos anos, as perseguições tinham me impedido de fazer-Ihe uma visita: eu tinha suportado, em vários lugares, exilado de minha pátria por aqueles que partilham da heresia (Greg. Nis., Vit. Mac., 15, 1-9).

E de fato, depois dos preparativos rituais [que precedem as reuniões conciliares], eu me vi com os outros bispos convocados para esse objetivo, coletar os votos concernentes à eleição. Ora, o resultado da eleição se concretizou e o eleito fui eu e, infelizmente sem imaginar, eu fui preso em uma armadilha por minhas próprias asas! Logo após a eleição, violências, armas, ataques, fiscalização, escolta militar: o próprio

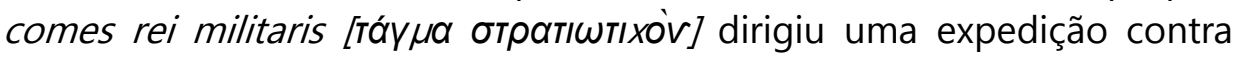
nós, ${ }^{3}$ colocando contra nós a autoridade do governador, reunindo todos

3 Tradução a partir de Maraval (1990, p. 254, nota 1). A cidade de Sebástia era a capital da Armênia Primeira, uma província de fronteira com presença de aquartelamentos militares: daí a vinda de um funcionário imperial militar ser verossímil nesse contexto. 
os meios para exercer contra nós sua tirania (Greg. Nis., Ep., 19,15-16, datada no início de 380 d. C.). ${ }^{4}$

A partir desses dois momentos, primeiro de enfraquecimento da imagem de Gregório de Nissa perante seus pares e depois de participação ativa do bispo na corte de Teodósio I, construímos a hipótese central de nossa investigação, tendo como referência o período de produção e circulação do discurso Contra Eunômio, de Gregório de Nissa. Conforme os testemunhos das epístolas 13, 15, 26, 27, 29 e 30 do próprio Gregório, identificamos os momentos de produção e de circulação inicial do seu discurso: ou seja, de 378 a 383 d. C., conforme os excertos abaixo:

Eu recebi o tratado de Eunômio na mesma época da morte do santo Basílio, quando o meu coração ainda estava ardendo de dor e transbordava de aflição dado o infortúnio comum a todas as igrejas, pois Eunômio não somente escreveu o que lhe parecia essencial a sua própria doutrina, mas despendeu grande parte da sua energia em laboriosos escritos e insultos contra nosso pai (Greg. Nis., Ep., 29, 3, datada em 380 d. C.).

No meu retorno da Armênia [onde ficou preso], eu mal conseguia encontrar tempo livre para montar as notas de minha resposta a Eunômio, como a tua sabedoria aconselha. Assim, agora meu trabalho finalmente resultou na composição de um tratado, e o tratado já se tornou um volume (Greg. Nis., Ep., 29, 1, datada em 378-379 d. C.).

Eu não deixarei sem defesa a reputação do grande [Basílio], denegrida pelas blasfêmias desse inimigo, nem dispensarei a polêmica deste assunto. De outro lado, preciso refletir atentamente [...] porque nosso tratado dirigido a este adversário se propõe a dois motes: defender as calúnias dirigidas contra nós e resguardar a nosso incólume doutrina (Greg. Nis., Ep., 29, 3-4 datada em 380-381 d. C., antes do Concílio de Constantinopla).

\section{Considerações finais}

Mesmo após a fixação oficial do cristianismo, em 381 d. C., por meio da constitutio XVI, 1, 2, ser ortodoxo era um assunto complexo e de difícil definição. $\mathrm{Na}$ prática, é de nosso conhecimento que o arianismo e outros tipos de cristianismos

\footnotetext{
${ }^{4}$ A repetição de palavras, nesse caso o pronome nós, é proposital. Trata-se de uma figura retórica denominada círculo [xúx\os] cf. MARAVAL, 1971, p. 140, nota 1.
} 
sobreviveram no Império Romano, principalmente no Ocidente até meados do século VII d. C. Para tentar resolver essas questões, 21 dias após o término do Concílio de Constantinopla, em 381 d. C., os imperadores Graciano, Valentiniano II e Teodósio I promulgaram a já citada constitutio na qual nomearam alguns bispos como exemplo e juízes, como "restauradores da fé nicena". Nessa lei, encontramos o nome de Gregório de Nissa como referencial do que deveria, segundo o poder imperial, ser um cristão correto, alguém capaz de atender as especificações da visão de império desses governantes. Daí nossa hipótese estar ligada a essa nomeação: do exílio a exemplo e juiz da ortodoxia, Gregório de Nissa conseguiu reafirmar a sua posição dentre seus pares. Para tanto, acreditamos, que o seu discurso Contra Eunômio exerceu um papel fundamental nesses acontecimentos.

\section{Referências}

\section{Documentação primária impressa}

BASILE DE CESARÉE. Lettres. Texte établi et traduit par Yves Courtonne. Paris: Les Belles Lettres, 1957-1966, v. 3.

CODE THEODOSIEN - LIVRE XVI. Les lois religieuses des empereurs romains de Constantin à Théodose II (312-438). Texte latin: Theodor Mommsen. Traduction: Jean Rougé. Introduction et notes par Roland Delmaire avec la collaboration de François Richard et d'une équipe du GDR 2135. Introdution, notes e index par Élisabeth Mangnou-Nortier. Paris: Les Éditions du Cerf, 2002, v. 1.

GRÉGOIRE NAZIANZE, Saint. Lettres. Texté établi et traduit par Paul Gallay. Paris: Les Belles Lettres, 1964, v. 2.

GRÉGOIRE DE NYSSE. Contre Eunome I. 1-146. Texte grec de W. Jaeger (GNO I,1). Introduction, traduction et notes par Raymond Winling. Paris: Les Éditions du Cerf, 2008.

GRÉGOIRE DE NYSSE. Contre Eunome I. 147-691. Texte grec de W. Jaeger (GNO I,1). Introduction, traduction et notes par Raymond Winling. Paris: Les Éditions du Cerf, 2010.

GRÉGOIRE DE NYSSE. Lettres. Introduction, texte critique, traduction, notes et index par Pierre Maraval. Paris: Les Éditions du Cerf, 1990. 
GRÉGOIRE DE NYSSE. Vie de sainte Macrine. Introduction, texte critique, traduction, notes et index par Pierre Maraval. Paris: Les Éditions du Cerf, 1971.

GREGORY OF NYSSA. The Letters. Introduction, translation and commentary by Anna M. Silvas. Leiden, Boston: Brill, 2007.

\section{Obras de apoio}

CAMERON, A. Christianity and the rhetoric of Empire: the development of Christian discourse. Berkely, Los Angeles, London: University of Califórnia Press, 1994.

CARVAlHO, M. M. de. Paideia e retórica no século IV d. C.: a construção da imagem do imperador Juliano segundo Gregório Nazianzeno. São Paulo: Annablume, 2010.

DROBNER, H. R. Manual de patrologia. Petrópolis, RJ: Vozes, 2003.

DELMAIRE, R. Exil, relégatio, déportation dans la législation du Bas-Empire. In: BLAUDEAU, P. Exil et relégation les tribulations du sage, et du Saint durant I'Antiquité Romaine et Chrétienne (Ier-VIe s.ap.J.-C.). Paris: De Boccard, 2008, p. 115-132.

ESCRIBANO PAÑO, M. V. La imagen del herético en la Constitutio XVI,5,6 (381) del Codex Theodosianus. Antig. Crist., Murcia, p. 475-498, 2006, v. 23. . Intolerancia religiosa y marginación geográfica en el s. IV d. C.: los exílios de Eunomio de Cízico. Studia historica. Historia antigua, Salamanca, n. 21, p. 177207, 2003.

FIGUEIREDO, D. A controvérsia nestoriana e suas implicações político-administrativas nas cartas de Cirilo de Alexandria (séc. $V$ d. C.). 2012. Dissertação de Mestrado em História. Faculdade de Ciências Humanas e Sociais, Universidade Estadual Paulista, Franca, São Paulo, 2012.

HAMMAN, A. G. Os padres da Igreja. São Paulo: Paulinas, 1983.

HANSON, R. P. C. The search for the Christian doctrine of god: the arian controversy 318-381. Scotland: T\&T Clark, 1997.

MORESCHINI, C.; NORELLI, E. (orgs.). História da literatura cristã antiga grega e latina. São Paulo: Loyola, 2000.

SILVA, G. V. da. A relação Estado/Igreja no Império Romano. (séculos III e IV). In: SILVA, G. V. da; MENDES, N. M. (orgs). Repensando o Império Romano: perspectiva socioeconômica, política e cultural. RJ: Mauad; Vitória: EDUFES, 2006, p. 241-266. 
SPANNEUT, M. Os Padres da Igreja: séculos IV-VIII. São Paulo: Loyola, 2002, v. 2.

SPINELLI, M. Helenização e recriação de sentidos: a filosofia na época da expansão do cristianismo, séculos II, III e IV. Porto Alegre: EDIPUCRS, 2002.

MATEO-SECO, L. F.; MASPERO, G. The Brill dicionary of Gregory of Nyssa. Leiden, Boston: Brill, 2010.

VAN NUFFELEN, P. Arius, Athanase et les autres: dimensions juridiques et politiques du retour d'exil ai IVe siècle. In: BLAUDEAU, P. Exil et relégation les tribulations du sage, et du Saint durant l'Antiquité Romaine et Chrétienne (Ier-VIe s.ap.J.-C.). Paris: De Boccard, 2008, p. 147-175. 